\title{
ANALYSIS OF ROUGHNESS PARAMETERS DETERMINING TRIBOLOGI- CAL PROPERTIES IN HARD TURNED SURFACES
}

\author{
VIKTOR MOLNÁR*1 AND ISTVÁN SZTANKOVICS ${ }^{1}$ \\ ${ }^{1}$ Institute of Manufacturing Science, University of Miskolc, Egyetemváros, Miskolc, 3515, HUNGARY \\ Hard-machined components built into automotive industrial products play an important role because they incorporate \\ working surfaces. The machining of them is crucial; the accuracy, surface quality and lifetime have to be ensured. In \\ this paper the tribological properties of hard-turned surfaces are characterized and analyzed based on 3D and 2D sur- \\ face roughness parameters. Functional parameters that provide quantitative information about the wear resistance and \\ fluid retention of the machined surfaces were studied. The aim of the study was to summarize the relevant roughness \\ parameters in terms of the functionality of the surfaces and to collect experimental results for their application.
}

Keywords: wear-resistance, hard turning, surface roughness

\section{Introduction}

Many machined surfaces incorporate working surfaces, which move relative to other surfaces. The analysis and development of such surfaces is important because the surface quality $[1,2]$ and, within this parameter, the topographical characteristics $[3,4]$ by and large determine the lifetime of parts [5-7]. The characterization of surface topography is highlighted in the automotive industry, that is, predicting the values of roughness parameters [8] and the effect of technological data on the topography are determining factors in the design of machined parts [9]. Due to the development of superhard materials, the machining of hardened surfaces by single-point tools has become more common in recent decades [10].

In this paper, the topography of internal cylindrical surfaces machined by hard turning is analyzed from a tribological point of view. Tribology focuses on the friction, wear and friction-reducing characteristics of surfaces. By analyzing surface topography with the help of several available surface roughness parameters, the wear resistance as well as load-bearing and fluid-retention capacities of surfaces can be characterized [11]. These parameters have been analyzed in numerous studies which only focus on certain parameter groups, e.g. Rk or volume parameters [12-15].

The aim of the present study is to summarize and compare most of the roughness parameters that describe tribological characteristics. These are mainly the areal (3D) roughness parameters because of their exactness [16-18]. If a parameter has a corresponding line parameter (2D), it is also analyzed. While less exact than 3D

\footnotetext{
*Correspondence: viktor.molnar@uni-miskolc.hu
}

results, $2 \mathrm{D}$ studies can provide useful practical information and are less time-consuming. Although certain parameters can be considered as more accurate due to their modernity, e.g. volume parameters, most parameters can provide at least directions with regard to the mentioned tribological characteristics.

\section{Tribology-oriented roughness parame- ters}

The simplest information is provided by the maximum peak height $(\mathrm{Sp})$ and maximum valley depth $(\mathrm{Sv})$ within the group of height parameters. A higher peak maximum height could be indicative of a relatively long wear-in phase and a higher maximum valley depth of a higher fluid-retention capacity. The skewness (Ssk) and kurtosis (Sku) parameters are also regarded as height parameters. A negative Ssk, e.g,. a burnished surface, means a better fluid-retention capacity comparative to the positive values of highly peaky surfaces. In the case of a zero or negative Ssk value, the load-bearing area of the surface is greater, therefore, its wear resistance is also greater [3]. This effect is enhanced by an Sku of 3 or lower, which is indicative of a relatively filled surface [19]. These characteristics are summarized in Fig. 1 based on 2D profile parameters.

The Abbott-Firestone curve and the related Sk parameters (Fig. 2) typically help to analyze the functional and tribological properties of a surface [21]. The shape of the curve itself draws attention to some remarkable topographic characteristics. The curve of a random (isotropic) surface, e.g. the ground, is entirely analogous to that of a normal distribution. In the case of periodic, e.g. hard- 


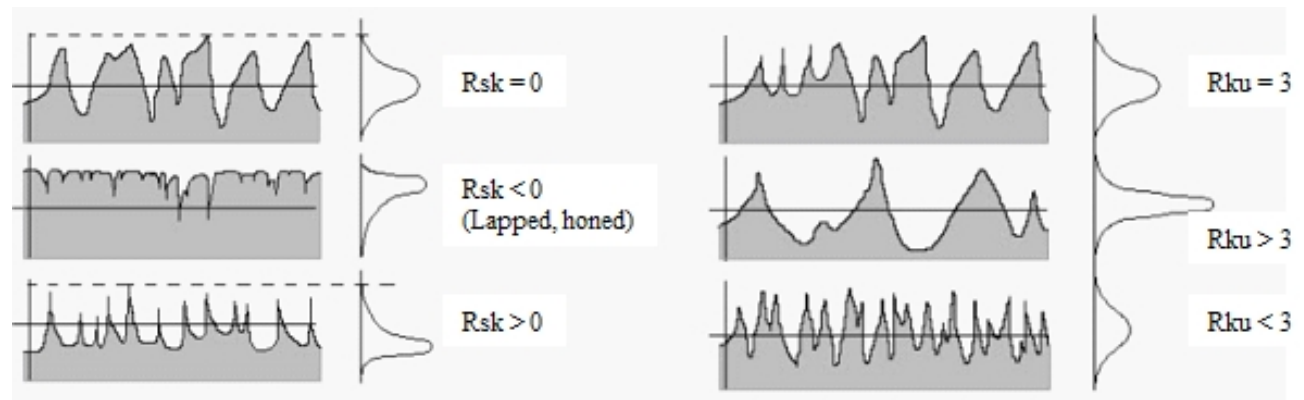

Figure 1: The ranges of the Rsk and Rku parameters for different surface topographies [20]

Table 1: Effects of changes in the parameters determining tribological properties

\begin{tabular}{l|l|l}
\hline Change in roughness parameter & Sp: $\downarrow ;$ Ssk: $\downarrow / \leq 0 ;$ Sku: $\downarrow /<3 ;$ & Sv: $\uparrow ;$ Ssk: $\downarrow / \leq 0 ;$ Svk: $\uparrow ;$ Sa2: \\
& Spk: $\downarrow ;$ Sa1: $\downarrow ;$ Vmp: $\downarrow ;$ Sbi: $\uparrow$ & $\uparrow ;$ Vvc: $\uparrow ;$ Vvv: $\uparrow ;$ Sci: $\uparrow ;$ Svi: $\uparrow$ \\
\hline $\begin{array}{l}\text { Change in tribological character- } \\
\text { istics }\end{array}$ & $\begin{array}{l}\text { Wear resistance and/or load- } \\
\text { bearing capacity increases }\end{array}$ & $\begin{array}{l}\text { Fluid-retention capacity in- } \\
\text { creases }\end{array}$ \\
\hline
\end{tabular}

turned, surfaces, the change in the gradient of the curve is uneven and the curve is asymmetrical. The procedures that reduce or eliminate the surface peaks, e.g. diamond or ball burnishing, result in a plateaued topography and a filled surface [4,22], yielding a relatively straight middle section with a gradual gradient in the curve. In this case, since the material volume of the surface peaks is relatively low, the wear resistance of the surface is higher [11]. Concerning the Sk parameters, the value of the reduced peak height (Spk) is low. The increase in the reduced valley depth (Svk) indicates a higher fluid retention capacity [23]. In the analysis of Sk, volume parameters are also applied to the material volume of peaks (Sa1) and the void volume of valleys (Sa2) [24].

Although similar statements are valid for the volume parameters, this parameter group measures the magnitude of the peak and valley zones in a more exact manner. The lower the peak material volume (Vmp) is, the better its wear resistance capacity, moreover, the higher the core void volume $(\mathrm{Vvc})$ and valley void volume $(\mathrm{Vvv})$,

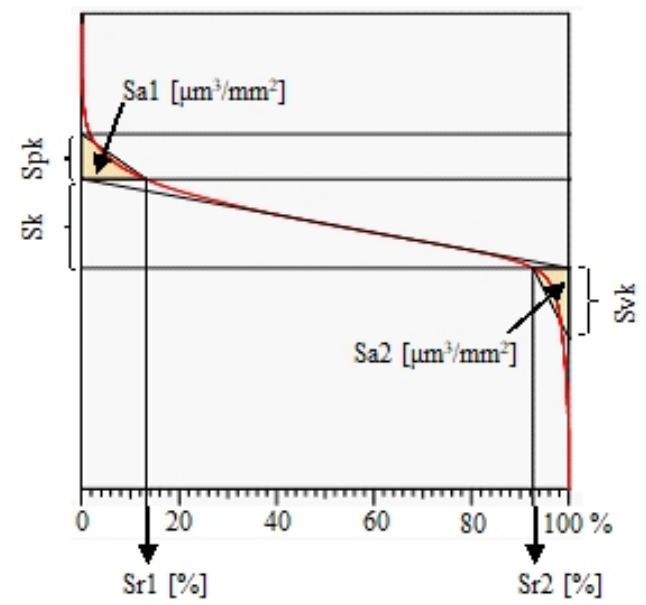

Figure 2: The Abbott-Firestone curve and the determination of the Sk parameters the better its fluid retention capacity [11]. In the volume analysis the peak zone is defined as the top $10 \%$ and the valley zone as the bottom $20 \%$ of the topography.

The so-called functional indices are less well-known or at least less frequently applied. Rather than being derived from the Abbott-Firestone curve, they are characterized by the load-bearing and fluid-retention capacities of the surfaces. The higher the surface bearing index (Sbi), the higher its load-bearing capacity, while the higher the core fluid retention (Sci) and the valley fluid retention (Svi) indices, the better its fluid retention capacity. These tribological properties are summarized in Table 1.

\section{Experimental conditions}

Internal cylindrical surfaces $\left(S_{1}, S_{2}\right.$ and $\left.S_{3}\right)$ of three parts were machined by hard turning. Various feeds resulted in different topographies when the other cutting parameters were fixed. The cutting experiments were carried out by a hard machining tool enter type EMAG VDC 400. The applied insert was of the type CCGW 09T308 NC2 and the tool holder of the type E25T-SCLCR 09-R. The cutting data are summarized in Table 2.

The surfaces were bores of gearwheels built into transmission systems. The parts were composed of the steel $20 \mathrm{MnCr} 5$. The physical and mechanical properties as well as the chemical composition of this steel are summarized in Table 3. The diameters of the machined bores were $d=88 \mathrm{~mm}$ and their lengths were $L=34 \mathrm{~mm}$.

The surface roughness measurements were carried out on an AltiSurf 520 measuring machine using a CL2type optical sensor with a nominal measuring range of $0-300 \mu \mathrm{m}$. The resolution along the $z$ axis was $0.012 \mu \mathrm{m}$ and $5 \mu \mathrm{m}$ along the $x$ and $y$ axes. The scanned area was $4.8 \times 2.8 \mathrm{~mm}^{2}$. Gaussian filtering was applied to the evaluation and the cut-off wavelength was $\lambda_{c}=0.8$ $\mathrm{mm}$. For the purpose of evaluating the area parameters, a $2 \times 2 \mathrm{~mm}^{2}$ area was taken into account and the evaluation 
Table 2: Cutting data of the machined surfaces

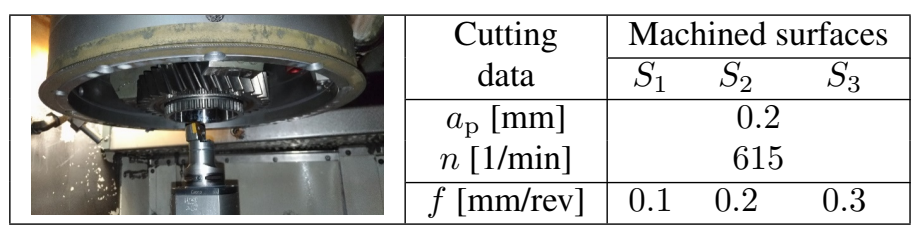

Table 3: Physical and mechanical properties as well as the chemical composition of the machined workpieces

\begin{tabular}{|c|c|c|c|c|c|c|c|}
\hline $\begin{array}{c}\text { Yield Strength } \\
\sigma_{\mathrm{s}}(\mathrm{MPa}) \\
\end{array}$ & $\begin{array}{c}\text { Tensile Strength } \\
\sigma_{\mathrm{b}}(\mathrm{MPa})\end{array}$ & $\begin{array}{c}\text { Hardness } \\
\text { HRC }\end{array}$ & Ther & $\begin{array}{r}\text { rmal Cond } \\
k(\mathrm{~W} / \mathrm{mr} \\
\end{array}$ & $\begin{array}{l}\text { uctivity } \\
\text { K) }\end{array}$ & $\begin{array}{c}\text { Density } \\
\rho\left(\mathrm{g} / \mathrm{cm}^{3}\right) \\
\end{array}$ & $\begin{array}{c}\text { Elastic Modulus } \\
E(\mathrm{GPa}) \\
\end{array}$ \\
\hline 1034 & 1158 & $62-64$ & & 11.7 & & $7.7-8.03$ & $190-210$ \\
\hline $\mathrm{C}$ & $\mathrm{Mn}$ & $\mathrm{Cr}$ & $\mathrm{Si}$ & $\mathrm{Cu}$ & $\mathrm{S}$ & $\mathrm{P}$ & $\mathrm{Al}$ \\
\hline $0.17-0.22$ & $1.1-1.4$ & $.0--1.3$ & $\leq 0.4$ & $\leq 0.4$ & $\leq 0.035$ & $\leq 0.025$ & $0.02-0.04$ \\
\hline
\end{tabular}

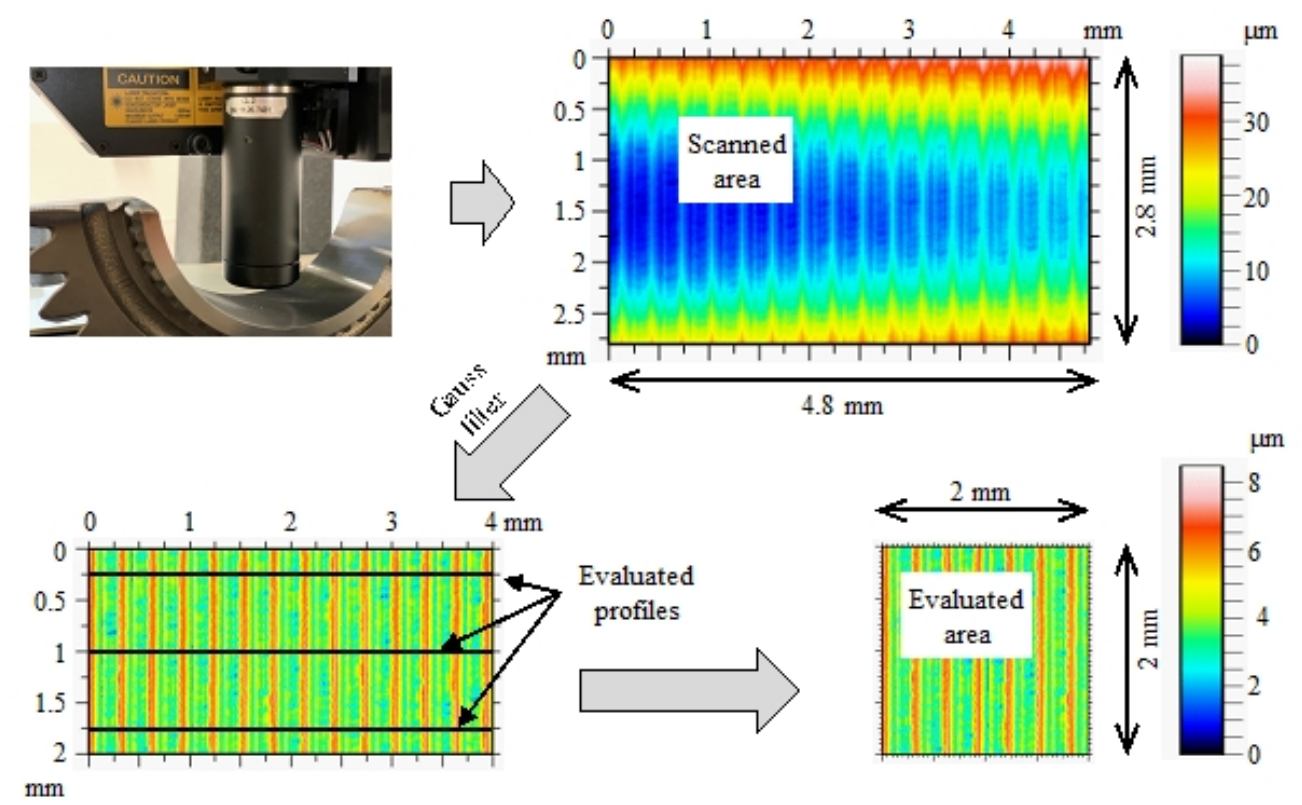

Figure 3: Evaluation area and profiles applied to the surface topography analysis

length for the line parameters was $l_{\mathrm{n}}=4 \mathrm{~mm}$. The analysis of the line parameters was carried out based on the average surface roughness values calculated from three profiles per surface. The line profile was extracted from the $3 \mathrm{D}$ area. The measurement setup, evaluation area and location of the 2D profiles are presented in Fig. 3. For the analysis of the 3D parameters, the geometrical product specification (GPS) standard ISO 25178 was used, while the standards ISO 4287 and ISO 13565-2 were used for the 2D parameters. The analyzed functional indices are defined by the standard EUR 15178N.

\section{Results and discussion}

\subsection{Surface characteristics}

Surfaces machined by hard turning exhibit periodic topography in contrast to random surfaces such as ground surfaces. In metrology, this characteristic can be expressed by the degree of isotropy as a percentage or by using the spatial parameter, $\operatorname{Str}$ (ranging from 0 to 1 ). The analyzed surfaces are definitely anisotropic; their values vary between 1.46 and $4.28 \%$. The degree of isotropy increases as the feed rate increases. The specific direction of measurement $(X)$ is identical to the direction of the feed, which is perpendicular to the cutting speed vector. In this direction, the roughness height of the turned surface is at its maximum. This direction of measurement is important because the direction of the extracted $2 \mathrm{D}$ profiles is $X$. The dominant texture direction (lay) varies between $90^{\circ}$ and $90.05^{\circ}$, which demonstrates the accuracy of the measurements. In Table 4, the isotropy of the analyzed surfaces and the texture directions are summarized.

Frequency analysis was performed for additional characterization of the surfaces. In Fig. 4, the Power Spectral Densities (PSD) of the surfaces are presented. It can be observed that the wavelengths are identical to the feed rate values. Additional components appear as periodic noises in the analyses. They might result from fur- 
Table 4: Texture direction and isotropy of the analyzed surfaces

\begin{tabular}{|c|c|c|}
\hline \multicolumn{3}{|c|}{ Surface } \\
\hline$S_{1}$ & $S_{2}$ \\
\hline Isotropy: $1.4576 \%$ & Isotropy: $1.8917 \%$ & $S_{3}$ \\
\hline First direction: $89.9956^{\circ}$ & First direction: $89.9973^{\circ}$ & First direction: $90.0461^{\circ}$ \\
\hline
\end{tabular}
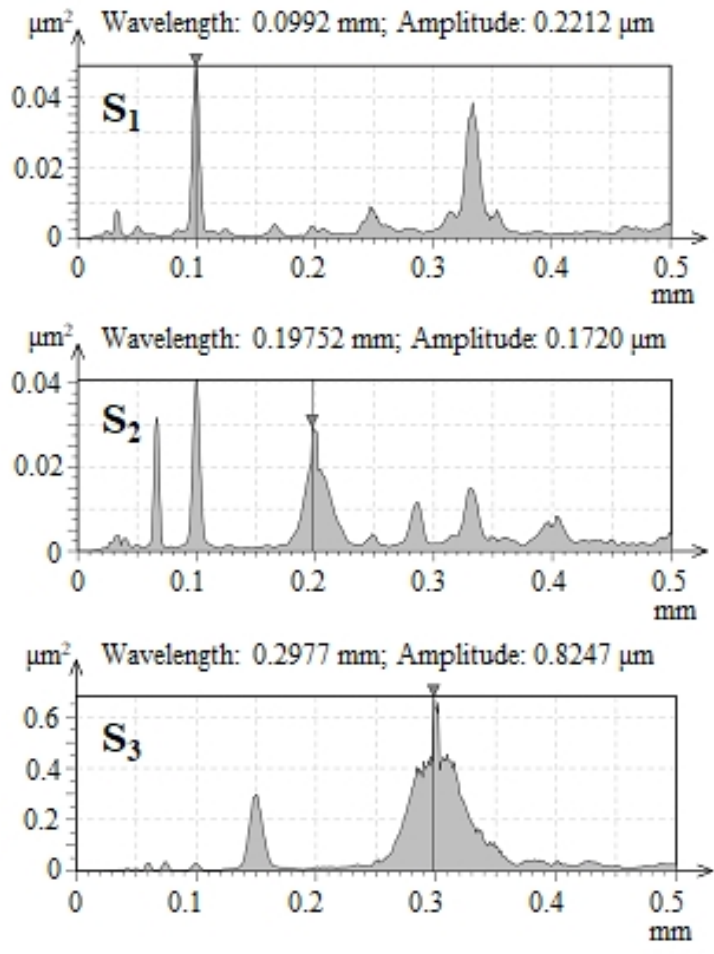

Figure 4: Power Spectral Density (PSD) analysis of the surfaces

ther topographic characteristics of the surfaces or from mechanical circumstances of the machining.

In Figs. 5 and 6, the simple height parameters of the surfaces are demonstrated for 3D and 2D measurements, respectively. The arithmetical mean height ( $\mathrm{Sa}$ and $\mathrm{Ra}$ ), the maximum height ( $\mathrm{Sz}$ and $\mathrm{Rz}$ ), the maximum peak height ( $\mathrm{Sp}$ and $\mathrm{Rp}$ ) and the maximum valley depth $(\mathrm{Sv}$ and Rv) have similar values for the different surface topographies, that is, $S_{1}(f=0.1 \mathrm{~mm} / \mathrm{rev})$ and $S_{2}(f=0.2$ $\mathrm{mm} / \mathrm{rev})$. This phenomenon highlights the necessity of including additional parameters in the topography in order to characterize it in more detail.

By analyzing the deviations in the 2D and 3D height parameters, it can be stated that the maximum peak height $(\mathrm{Sp})$ is $1.2-2.2$ times higher than the mean of the Rp values obtained by averaging the three $2 \mathrm{D}$ measurements. This multiplier varies between 1.9 and 2.5 in terms of $\mathrm{Sv}$ and $\mathrm{Rv}$ for the surfaces machined using three different feed rates. The maximum height $(\mathrm{Sz})$ is $1.5-2.3$ times higher than the average of the three $\mathrm{Rz}$ values. By comparing the arithmetical mean heights ( $\mathrm{Sa}$ and $\mathrm{Ra}$ ), it was found that the $3 \mathrm{D}$ values are higher than the $2 \mathrm{D}$ ones. The Sa values are $8-15 \%$ higher than the Ra ones and the percentage differences are higher when lower feed rates were applied (Fig. 7).

\subsection{Analysis of tribological parameters}

The parameters characterizing tribological properties are found in the height, Sk and volume parameter groups as well as among the functional indices. In Fig. 8, the 3D parameters that provide information about the wear resistance are summarized for the analyzed surfaces. The lower values of $\mathrm{Sp}, \mathrm{Spk}, \mathrm{Sa} 1$ and Vmp indicate better wear resistance. For all four parameters, it can be stated that surface $S_{2}$ machined at $f=0.2 \mathrm{~mm} / \mathrm{rev}$ is the most wear-resistant and surface $S_{3}$ machined at $f=0.3$ $\mathrm{mm} / \mathrm{rev}$ is the least. The same is observed according to the Ssk parameter. However, based on the Sku parameter, the most wear-resistant surface is $S_{3}$, which is machined at $f=0.3 \mathrm{~mm} / \mathrm{rev}$. The values of these two parameters indicate that the surfaces that have more filled peak zones and, therefore, whose peaks wear out faster are more wear-resistant. The surface is characterized by the Sbi parameter according to a different method: it is calculated as the ratio of the Sq parameter to the material volume in the top $5 \%$ of the surface. As a consequence, the surface machined at a high feed rate $(0.3 \mathrm{~mm} / \mathrm{rev})$ is ranked first in terms of wear resistance. It should be noted that among the analyzed parameters, the dimensions of $\mathrm{Sp}$ and Spk denote length, of Sa1 and Vmp represent volume, while Ssk, Sku and Sbi are non-dimensional. If the volume parameter $\mathrm{Vmp}$ is considered to be the base due to its modernity and accuracy, the order of the surfaces in terms of wear resistance is $S_{2}, S_{1}$ and $S_{3}$. This is confirmed by the order of the parameters $\mathrm{Sp}, \mathrm{Spk}, \mathrm{Sa} 1$ and Ssk.

The parameters that provide information about the fluid-retention capacity of the surfaces are summarized in Fig. 9. The parameters Sv, Svk, Sa2, Vvv and Svi characterize the valley zone and the fluid-retention capacity increases as their values increase. The core zone 


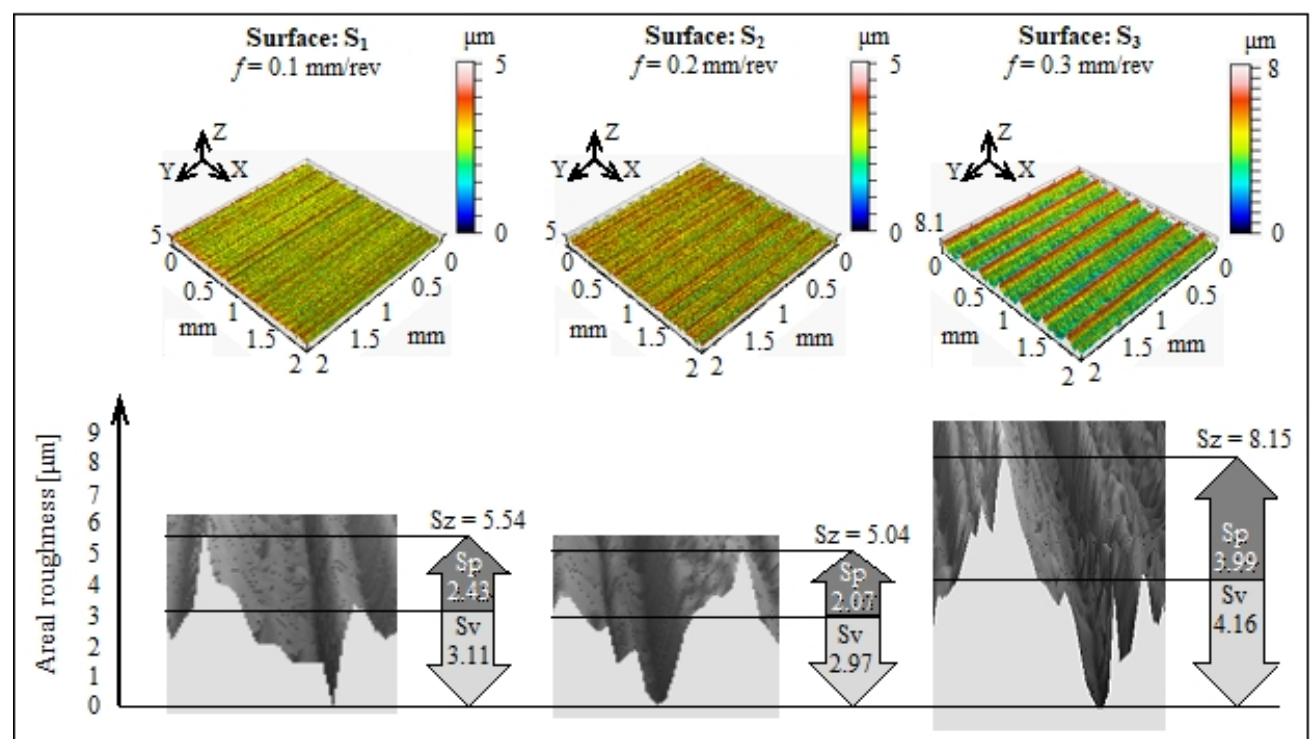

Figure 5: 3D height parameters of the analyzed surfaces

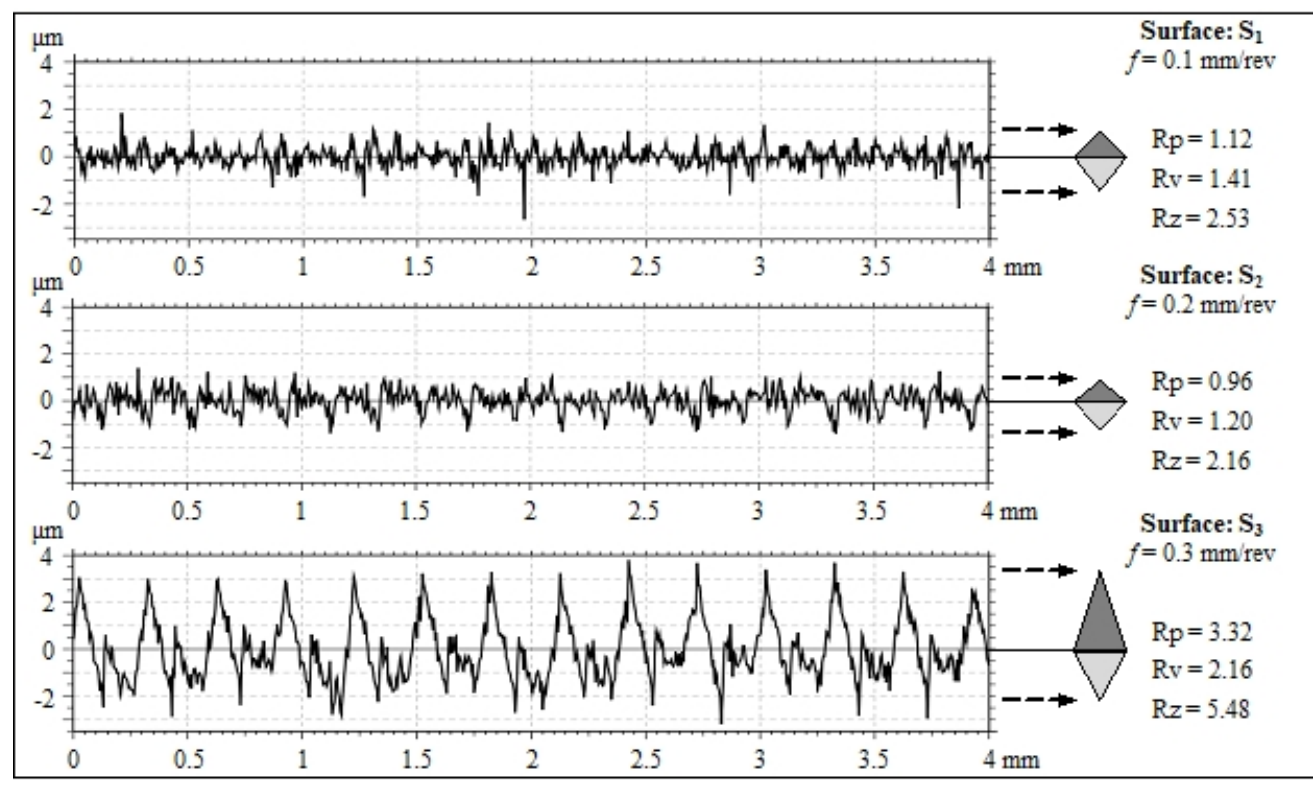

Figure 6: The profiles extracted from the scanned surface (one profile per surface) and their 2D height parameters (average of the data from three profiles)

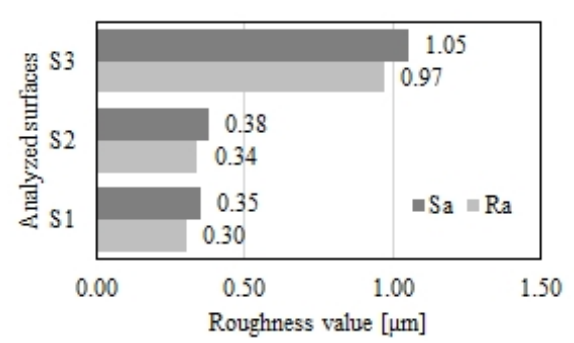

Figure 7: Comparison of the 2D and 3D arithmetical mean heights

is characterized by the parameters $\mathrm{Vvc}$ and Sci, moreover, higher values indicate greater fluid-retention capacities. This property is better in the case of low or neg- ative Ssk values. Concerning the order of the surfaces, deviations can be observed, which may be derived from the different dimensions of the parameters. If the parameter $\mathrm{Vvv}$ is considered to be the base, the order of the surfaces is $S_{3}, S_{2}$ then $S_{1}$. This is not confirmed by any other parameters. Regarding the valley zone, the parameters Ssk, Sa2 then Svi yield the identical order, that is, $S_{2}, S_{1}$ then $S_{3}$. Based on the fluid-retention capacity of the core zone, that is, parameter $\mathrm{Vvc}$, the order is $S_{3}, S_{2}$ then $S_{1}$. This order is confirmed by the other parameter of the core zone, Sci.

By analyzing the 2D profile parameters (Fig. 10), it was found that all of them provide the same order as their 3D counterparts. By considering the 3D values as bases, the following can be stated based on the $2 \mathrm{D}$ pa- 

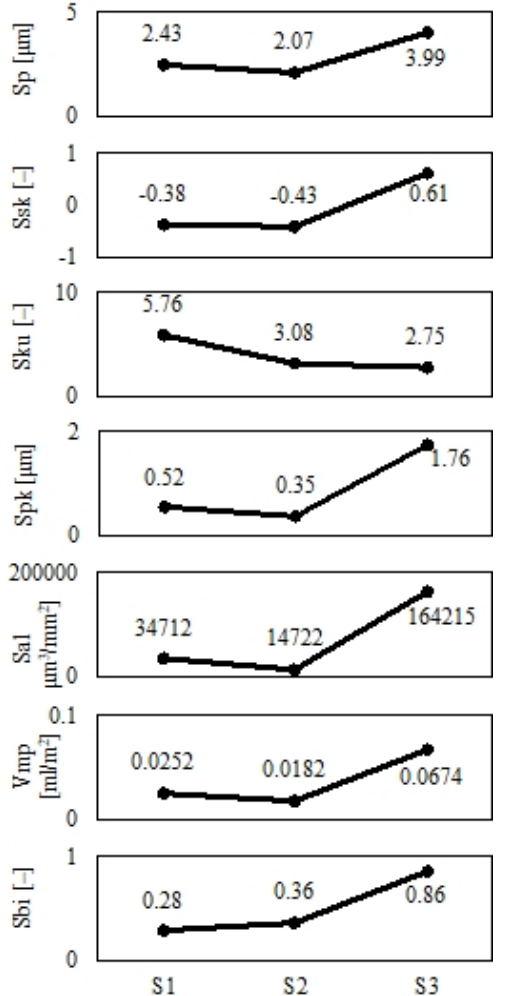

Figure 8: 3D roughness parameters characterizing wear resistance

rameters with regard to the three surfaces. The values of the parameters $\mathrm{Rp}$ are 46 to $83 \%$ of those of $\mathrm{Sp}$. The rate of the parameter $\mathrm{Rv}$ varies between 40 and $52 \%$, while those of Rsk and Rku are $21-143 \%$ and $71-112 \%$, respectively. The differences in terms of Tpk and Rvk are smaller, namely $90-112 \%$ and $90-105 \%$, respectively. In Table 5, the order of the surfaces is summarized based on the findings detailed above concerning wear resistance and fluid-retention capacity.

\section{Conclusions}

From the analysis of the general characteristics of the surfaces, it was found that for the applied cutting data the hard-turned surface is anisotropic and the degree of isotropy varies between 1.5 and $4.3 \%$. The Power Spectral Density analysis clearly determined that the wavelengths are identical to the feed rates. The 3D height parameters (Sv, Sp, Sz, Sa) of the surfaces machined by lower feed rates, namely $f=0.1$ and $0.2 \mathrm{~mm} / \mathrm{rev}$, show absolute differences of between 5 and $17 \%$ and this difference in the case of the 2D parameters ( $R v, R p, R z, R a)$ varies between 11 and $17 \%$. By comparing the $3 \mathrm{D}$ and 2D parameters, it was found that the Sa value of the 3D measurement is at most $15 \%$ higher than the Ra value of the 2D measurement. The $\mathrm{Sv}, \mathrm{Sp}$ and $\mathrm{Sz}$ values can be up to 2.5 times higher than their $2 \mathrm{D}$ counterparts. From the analysis of the surface roughness parameters that indicate tribological properties, the following can be stated:
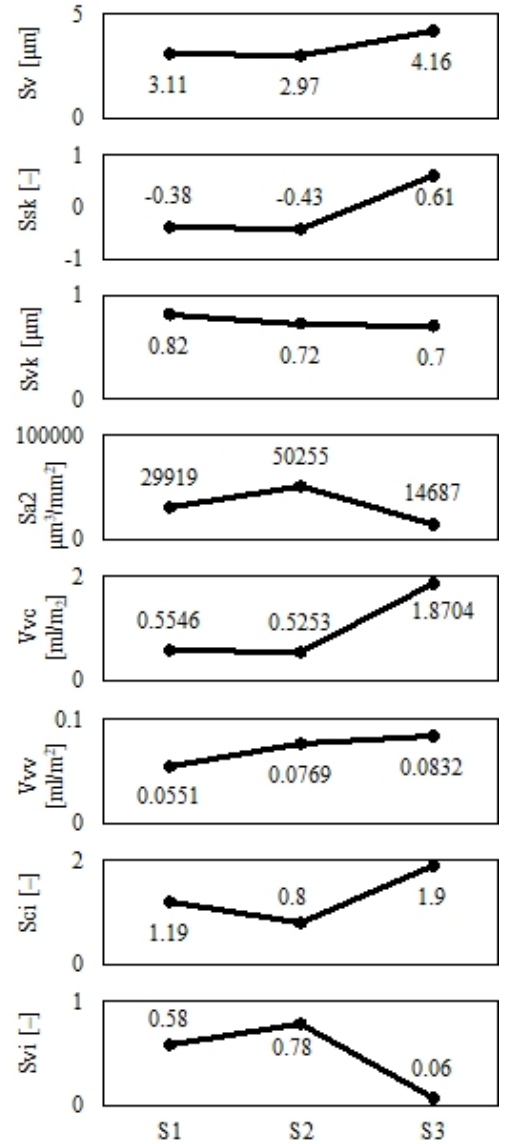

Figure 9: 3D roughness parameters characterizing fluidretention capacity

1. Based on the parameters that evaluate the roughness peaks and indicate the wear resistance (Sp, Ssk, Spk, Sa1 and Vmp), the most and least wear-resistant are the surfaces hard turned at feed rates of 0.2 and 0.3 $\mathrm{mm} / \mathrm{rev}$, respectively. The other parameters yielded different orders, which can be explained by their calculation methods.

2. The order of the surfaces with regard to the parameters of the core zone that indicate the fluid-retention capacity ( $\mathrm{Vvc}, \mathrm{Sci}$ ) is identical: the surfaces machined at feed rates of 0.3 and $0.2 \mathrm{~mm} / \mathrm{rev}$ exhibit the best and worst fluid-retention capacities, respectively.

3. The order of the surfaces with regard to the parameters of the valley zone that indicate the fluidretention capacity (Ssk, Sa2 and Svi) is identical: the surfaces machined at feed rates of 0.2 and 0.3 $\mathrm{mm} / \mathrm{rev}$ exhibit the best and worst fluid-retention capacities, respectively. The other parameters yielded different orders, which can be explained by their calculation methods.

Another useful research direction would be the comparison of different workpiece materials. In addition to this, based on systematic experimental design, carrying out 


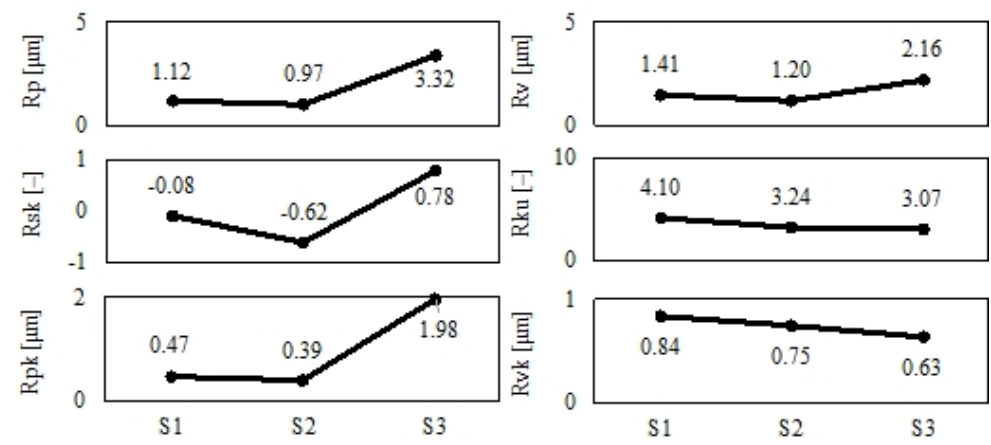

Figure 10: 2D roughness parameters characterizing wear resistance and fluid-retention capacity

Table 5: Order of the surfaces based on the analyzed tribological properties and roughness parameters

\begin{tabular}{cccccc}
\hline Peak parameter & Order & Valley parameter & Order & Core parameter & Order \\
\hline Sp & $S_{2}>S_{1}>S_{3}$ & Sv & $S_{3}>S_{1}>S_{2}$ & Vvc & $S_{3}>S_{1}>S_{2}$ \\
Ssk & $S_{2}>S_{1}>S_{3}$ & Ssk & $S_{2}>S_{1}>S_{3}$ & Sci & $S_{3}>S_{1}>S_{2}$ \\
Sku & $S_{3}>S_{2}>S_{1}$ & Svk & $S_{1}>S_{2}>S_{3}$ & & \\
Spk & $S_{2}>S_{1}>S_{3}$ & Sa2 & $S_{2}>S_{1}>S_{3}$ & & \\
Sa1 & $S_{2}>S_{1}>S_{3}$ & Vvv & $S_{3}>S_{2}>S_{1}$ & & \\
Vmp & $S_{2}>S_{1}>S_{3}$ & Svi & $S_{2}>S_{1}>S_{3}$ & & \\
Sbi & $S_{3}>S_{2}>S_{1}$ & & & & \\
\hline
\end{tabular}

machining experiments using various cutting parameter setups would lead to generalizable statements. Furthermore, why the fluid-retention capacity of the valley zone is characterized by relatively large deviations based on the different roughness parameters could be investigated.

\section{REFERENCES}

[1] Blawucki, S.; Zaleski, K.: The effect of the aluminium alloy surface roughness on the restitution coefficient. Adv. Sci. Technol. Res. J., 2015, 9, 6671 DOI: 10.12913/22998624/59086

[2] Gogolin, A.; Wasilewski, M.; Ligus, G.; Wojciechowski, S.; Gapinski, B.; Krolczyk, J.; Zajac, D.; Krolczyk, G.: Influence of geometry and surface morphology of the U-tube on the fluid flow in the range of various velocities. Measurement, 2020, 164, 108094 DOI: 10.1016/j.measurement.2020.108094

[3] Karkalos, N.E.; Karmiris-Obratanski, P.; Kurpiel, S.; Zagorski, K.; Markopoulos, A.P.: Investigation on the surface quality obtained during trochoidal milling of 6082 aluminum alloy. Machines, 2021, 9, 75 DOI: 10.3390/machines9040075

[4] Sagbas, A.: Analysis and optimization of surface roughness in the ball burnishing process using response surface methodology and desirability function. Adv. Eng. Softw., 2011, 42, 992-998 DOI: 10.1016/j.advengsoft.2011.05.021

[5] Linins, O.; Krizbergs, J.; Boiko, I.: Surface texture metrology gives a better understanding of the surface in its functional state. Key. Eng. Mater., 2013, 527, 167-172 DOI: 10.1016/j.precisioneng.2016.06.001

[6] Kundrak, J.; Nagy, A.; Markopoulos, A.P.; Karkalos, N.E.: Investigation of surface roughness on face milled parts with round insert in planes parallel to the feed at various cutting speeds. Cut. Tools Technol. Syst., 2019, 91, 87-96 DOI: 10.20998/20787405.2019.91.09

[7] Grzesik, W.; Rech, J.; Zak, K.: High-precision Finishing Hard Steel Surfaces Using Cutting, Abrasive and Burnishing Operations. Procedia Manuf., 2015, 1, 619-627 DOI: 10.1016/j.promfg.2015.09.048

[8] Felho, C.; Kundrak, J.: Characterization of topography of cut surface based on theoretical roughness indexes. Key Eng. Mater., 2012, 496, 194-199 DOI: 10.4028/www.scientific.net/KEM.496.194

[9] Kundrak, J.; Gyani, K.; Felho, C.; Deszpoth, I.: The effect of the shape of chip cross section on cutting force and roughness when increasing feed in face milling. Manuf. Techn., 2017, 17(3), 335-342 DOI: 10.21062/ujep/x.2017/a/1213-2489/MT/17/3/335

[10] Mamalis, A.G.; Kundrak, J.; Horvath, M.: On a novel tool life relation for precision cutting tools. J. Manuf. Sci. Eng., 2005, 127, 328-332 DOI: $10.1115 / 1.1794158$

[11] Grzesik, W.; Zak, K.; Kiszka, P.: Comparison of Surface Textures Generated in Hard Turning and Grinding Operations. Procedia CIRP, 2014, 13, 84 89 DOI: 10.1016/j.procir.2014.04.015

[12] Charles, A.; Elkaseer, A.; Thijs, L.; Hagenmeyer, V.; Scholz, S.: Effect of process parameters on the generated surface roughness of down-facing surfaces in selective laser melting. Appl. Sci., 2019, 9 , 1256 DOI: 10.3390/app9061256

[13] Zawada-Tomkiewicz, A.: Analysis of surface roughness parameters achieved by hard turning with 
the use of PCBN tools. Estonian J. Eng., 2011, 17, 88 DOI: 10.3176/eng.2011.1.09

[14] Pytlak, B.: The roughness parameters 2D and 3D and some characteristics of the machined surface topography after hard turning and grinding of hardened 18CrMo4 steel. Kom. Budowy Masz. PAN Oddz. $w$ Pozn., 2011, 31, 53-62 DOI: 10.2478/amst2014-0004

[15] Shivanna, D.; Kiran, M.; Kavitha, S.: Evaluation of 3D Surface Roughness Parameters of EDM Components Using Vision System. Procedia Mater. Sci., 2014, 5, 2132-2141 DOI: 10.1016/j.mspro.2014.07.416

[16] Przestacki, D.; Majchrowski, R.; MarciniakPodsadna, L.: Experimental research of surface roughness and surface texture after laser cladding. Appl. Surf. Sci., 2016, 388, 420-423 DOI: 10.1016/j.apsusc.2015.12.093

[17] Kumar, R.; Seetharamu, S.; Kamaraj, M.: Quantitative evaluation of 3D surface roughness parameters during cavitation exposure of $16 \mathrm{Cr}-5 \mathrm{Ni}$ hydro turbine steel. Wear, 2014, 320, 16-24 DOI: 10.1016/j.wear.2014.07.015

[18] Aidibe, A.; Nejad, M.K.; Tahan, A.; Jahazi, M.; Cloutier, S.G.: A Proposition for New Quality 3D Indexes to Measure Surface Roughness. Procedia CIRP, 2016, 46, 327-330 DOI: 10.1016/j.procir.2016.03.136

[19] Kovacs, Z., Viharos, Z.J., Kodacsy, J.: The effects of machining strategies of magnetic assisted roller burnishing on the resulted surface structure. Mater. Sci. Eng., 2018, 448, 012002 DOI: 10.1088/1757899X/448/1/012002

[20] Bitelli, G.; Simone, A.; Girardi, F.; Lantieri, C.: Laser Scanning on Road Pavements: A New Approach for Characterizing Surface Texture. Sensors, 2012, 12, 9110-9128 DOI: 10.3390/s120709110

[21] Chen, L.; Liu, Z.; Wang, B.; Song, Q.; Wan, Y.; Chen, L.: Surface Characterization and Tribological Performance of Anodizing Micro-Textured Aluminum-Silicon. Materials, 2019, 12, 1862 DOI: 10.3390/ma12111862

[22] Zhu, L.; Guan, Y.; Wang, Y.; Xie, Z.; Lin, J.; Zhai, J.: Influence of process parameters of ultrasonic shot peening on surface roughness and hydrophilicity of pure titanium. Surf. Coatings Technol., 2017, 317, 38-53 DOI: 10.1016/j.surfcoat.2017.03.044

[23] Suha, A.I.; Polycarpoua, A.A.; Conry, T.F.: Detailed surface roughness characterization of engineering surfaces undergoing tribological testing leading to scuffing. Wear, 2003, 255, 556-568 DOI: 10.1016/S0043-1648(03)00224-2

[24] Wojciechowskia, L.; Wieczorowskib, M.; Mathia, T.G.: Transition from the boundary lubrication to scuffing-the role of metallic surfaces morphology, Wear, 2017, 392-393, 39-49 DOI: 10.1016/j.wear.2017.09.011 